\title{
One-way barpress avoidance response: An elevated-lever effect
}

\author{
HEIDAR A. MODARESI \\ Winthrop College, Rock Hill, South Carolina
}

\begin{abstract}
Rats that could enter a safe place after depressing an elevated lever (about $22 \mathrm{~cm}$ above the floor) quickly learned to avoid shock, and an increase in shock intensity either improved or did not affect their avoidance performance. Whether or not the rats learned to avoid seemed unrelated to the amount of freezing during the early trials.
\end{abstract}

Rats experience great difficulty in learning a discriminated avoidance barpressing response, and they reach considerably lower levels of avoidance barpress performance than they do in other avoidance tasks (e.g., Modaresi, 1989c). Instead of depressing the lever manipulandum prior to shock stimulation in order to avoid shock, they normally freeze on or near the manipulandum-a response known to be the most prominent of the rat's speciesspecific defense reactions (Fanselow \& Lester, 1988). The innate tendency of the rat to freeze in a fearful situation like avoidance barpress learning is, therefore, thought to prevent the subject from acquiring an avoidance barpress response (Bolles, 1970).

Modaresi (1989a, 1989b) found that several changes in the traditional avoidance barpress situation substantially overcame the rat's avoidance barpress difficulty. They consisted of (1) the subject's entering a safe compartment behind the lever manipulandum immediately after a barpress response, and (2) the placing of the manipulandum at an elevated rather than a regular position, $17-22 \mathrm{~cm}$ rather than $9 \mathrm{~cm}$ above the floor.

The present studies had the following aims: (1) to investigate the prevalence of freezing in an avoidance barpress learning situation with a regular lever as opposed to one with an elevated lever, and (2) to determine whether the one-way avoidance barpress learning arrangement used in Modaresi (1989a, 1989b) is adversely affected by an increase in the shock intensity, as in the usual barpress avoidance task (e.g., see Bolles \& Warren, 1965; D'Amato \& Fazzaro, 1966), whether it is improved by such an increase, or whether it is unaffected by such an increase, as in a one-way running task (e.g., see Dieter, 1976).

\section{EXPERIMENT 1}

Experiment 1 was designed to assess the possibility that different levels of avoidance learning obtained between

This research was supported in part by grants from the Winthrop College Research Council and the Arts and Sciences Faculty Development Funds. Requests for reprints should be sent to Heider A. Modaresi, Department of Psychology, Winthrop College, Rock Hill, SC 29733. regular- and elevated-lever situations (Modaresi, 1989a, $1989 \mathrm{~b}$ ) are associated with different levels of freezing. If the prevalence of a freezing species-specific defense reaction (SSDR) is responsible for the rat's difficulty in avoidance barpress responding with a regular lever, then one may expect that a regular-lever situation will result in more freezing than an elevated-lever situation will; the difference in freezing should be present during the initial stage of training - that is, before the rates of avoidance barpressing in the two groups diverge, because differential freezing on subsequent trials may be a result rather than a cause of differential avoidance responding.

\section{Method}

Subjects and Apparatus. Twenty female albino rats, 90-110 days old, from the animal colony of Winthrop College, were used. The apparatus, which is fully described in Modaresi (1989b), consisted of a dark gray plastic enclosure with a grid floor. A horizontal platform just above the grid floor could slide in and out of the apparatus from under each of the two end walls. Each end wall could slide forward to the center of the apparatus and back to its original position. Each half of the apparatus could, therefore, be used as either a shock or a safe compartment by placing an end wall in the center and, respectively, removing or inserting a safe platform in that compartment between the center and the end wall. In the present studies, one half of the apparatus always functioned as a shock compartment and the other half as a safe compartment. A lever manipulandum (Coulbourn E23-26) could be centrally mounted at various heights on the end wall that separated the subject in the shock compartment from the safe compartment.

Procedure. The rats were randomly assigned to two groups ( $n s=$ $10)$ and were given 100 consecutive escape-avoidance conditioning trials. The two groups differed only in terms of whether they experienced a regular or an elevated lever location, respectively, $9 \mathrm{~cm}$ and $22.23 \mathrm{~cm}$ above the grid floor. Each trial consisted of removing the platform from under the subject in the to-be-shock compartment, then turning on a warning signal (WS) light for $15 \mathrm{sec}$ before administering a continuous .8 -mA shock to the grid floor. The nominal WS was the onset of a triplecue light (Coulbourn E11-02) on the end wall opposite the lever, $26 \mathrm{~cm}$ above the floor. The subject could avoid shock by depressing the manipulandum before shock onset or escape it after it was turned on. Both escape and avoidance responses terminated the WS and were immediately followed by the center partition's sliding back to its end position, thus allowing the subject to enter a safe platform behind it. The other end wall was moved across the shock compartment to the center position, confining the subject on the safe platform for an intertrial interval (ITI) of $60 \mathrm{sec}$. The subject was then automatically displaced back to the platform in the shock compartment by first sliding the center wall across the platform in the shock compartment and then sliding the other end wall across the safe compartment to the center position. The next 


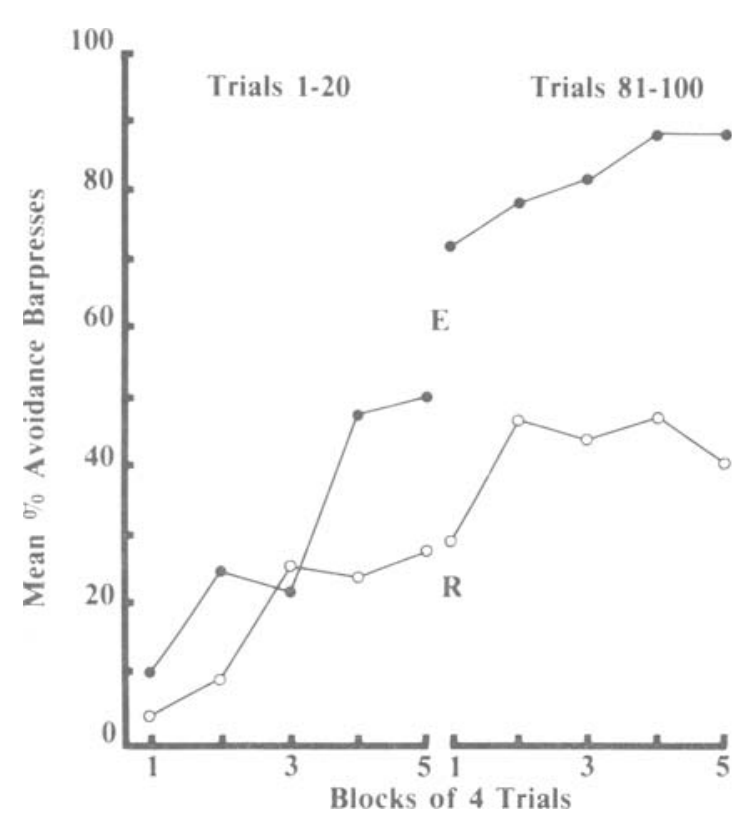

Figure 1. Experiment 1. The mean percentage of avoidance barpresses of Groups $R$ and $E$ in blocks of 4 trials during Trials 1-20 (left panel) and 81-100 (right panel).

trial began as before, $3 \mathrm{sec}$ later, with the removal of the platform from under the subject.

The subjects were videotaped during the first and last 20 trials, in the manner described in Modaresi (1989a). Whether the subject was freezing during the WS presentation was then determined via a sampling procedure (Fanselow, 1986), in which freezing (absence of any movement other than those associated with breathing) was recorded on every other second during the WS-shock (on escape trials) or WSresponse period (on avoidance trials).

\section{Results and Discussion}

As revealed in Figure 1, avoidance performance in the two groups did not substantially differ during the initial three blocks of trials in Period 1 (Trials 1-20), but, during Period 2 (Trials 81-100), only the E group showed substantial avoidance learning. A $2 \times 2 \times 5$ (lever $\times$ period $\times$ block of trials) analysis of variance (ANOVA) indicated that the effects of lever $[F(1,14)=4.50$, $p<.05]$, block of trials $[F(4,14)=8.00, p<.001]$, period $[F(4,14)=30.69, p<.001]$, and lever $\times$ period $[F(1,56)=5.25, p<.05]$ were significant. A NewmanKeuls test $(p=.05)$ revealed that Group E did not perform significantly better than Group $\mathrm{R}$ in any block of trials during Period $1\left(F_{\mathrm{S}}<1\right)$, but that it was superior to Group $\mathrm{R}$ on each block of trials in Period 2 $(p s<.01)$.

The freezing data are presented in Figure 2, in terms of the percentage of sampled $1-\mathrm{sec}$ periods in which the subject was freezing. These data reveal that percentage freezing in Groups $\mathrm{E}$ and $\mathrm{R}$ was remarkably comparable during Period 1 but was substantially greater in Group $\mathbf{R}$ during Period 2 . A $2 \times 2 \times 5$ ANOVA on these data resulted in a significant lever $\times$ period interaction $[F(1,56)=4.99, p<.04]$. This result substantiated the observation that comparable levels of freezing preceded differences in avoidance responding in the two groups, and that freezing was subsequently curtailed only in the group that acquired avoidance barpress responding.

\section{EXPERIMENT 2}

How does shock intensity affect a one-way elevated barpress avoidance task? In Experiment 2, we assessed this question. Although this avoidance task appears to entail the subject's performing a non-SSDR response, Modaresi (1989a) suggested that the presence of the lever near the top (exit) of the apparatus, as well as the spatial congruity of the lever and the safe compartment, may enable the subject to operate the manipulandum while engaging in SSDRs such as scratching or climbing the wall. If this analysis is true, one-way elevated barpress avoidance responding may be more like a one-way locomotion than a barpress task and, therefore, should be enhanced or left unaffected by an increase in shock intensity (Dieter, 1976; Moyer \& Korn, 1966).

\section{Method \\ Subjects and Apparatus. Thirty female albino rats from the animal colony of Winthrop College were used. They were 100-166 (average 155) days old and were maintained in the same manner as in Experi- ment 1 . The apparatus was the same one used in Experiment 1.}

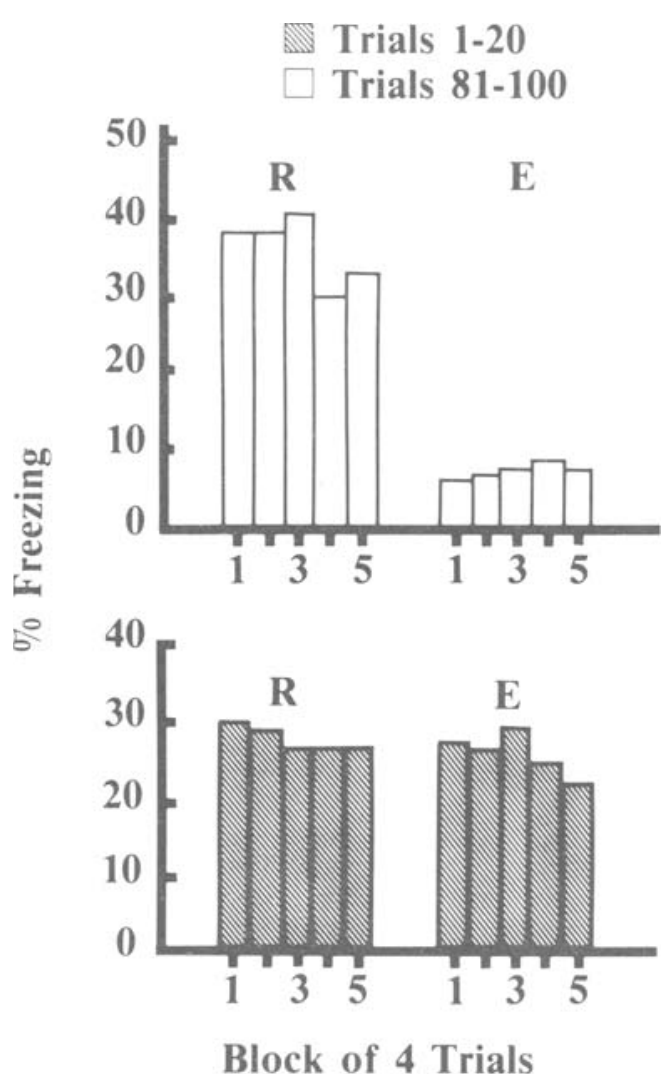

Figure 2. Experiment 1: The percentage of sampled freezing in Groups $R$ and $E$ during Trials 1-20 and 81-100. 
Procedure. The subjects were randomly assigned to three equally sized groups, and each group was given 80 consecutive escape-avoidance trials with an elevated lever in the same way as in Group E of Experiment 1. The only difference between groups was related to the intensity of shock, $.3 \mathrm{~mA}$ in Group .3, .8 mA in Group .8, and $1.5 \mathrm{~mA}$ in Group 1.5 .

\section{Results and Discussion}

As may be observed in Figure 3, the groups with the two highest levels of shock intensity quickly reached nearly perfect levels of avoidance responding. Considering the severity of shock used, the rapidity with which such high levels of avoidance barpressing was reached is unparalleled in the literature of avoidance barpress learning. Avoidance performance in the group with the weakest shock was comparable to that in the other groups during the first $\mathbf{4 0}$ trials, but it dropped sharply on later trials. A $3 \times 8$ (shock intensity $\times$ block of trials) ANOVA was performed on these data. The trial effect was highly significant $[F(7,189)=28.26, p<.001]$, but the effect of shock intensity $\times$ block of trials just reached an acceptable level of statistical significance $[F(14,189)=$ $1.75, p<.05]$. A Newman-Keuls test $(p=.05)$ revealed that the only difference between groups was between Groups 1.5 and .3 on Trial Block 6 . These results suggest that an increase in shock intensity does not hinder one-way elevated barpress avoidance responding as it does a regular barpress task, and, if anything, that it appears to have a somewhat positive effect.

\section{GENERAL DISCUSSION}

The present experiments replicated and extended previous work (Modaresi, 1989a, 1989b) on elevated barpress avoidance learning. As in the earlier studies, avoidance barpressing in a one-way training arrangement with an elevated lever was readily acquired, with a final level of performance that paralleled those normally obtained in a one-way running task.

The strength of freezing in the subjects during the initial trials did not seem to be causally related to the subsequent levels of avoidance performance. This conclusion follows the observation that, despite reaching considerably different levels of avoidance performance, Groups E and $R$ were remarkably comparable with respect to the prevalence of

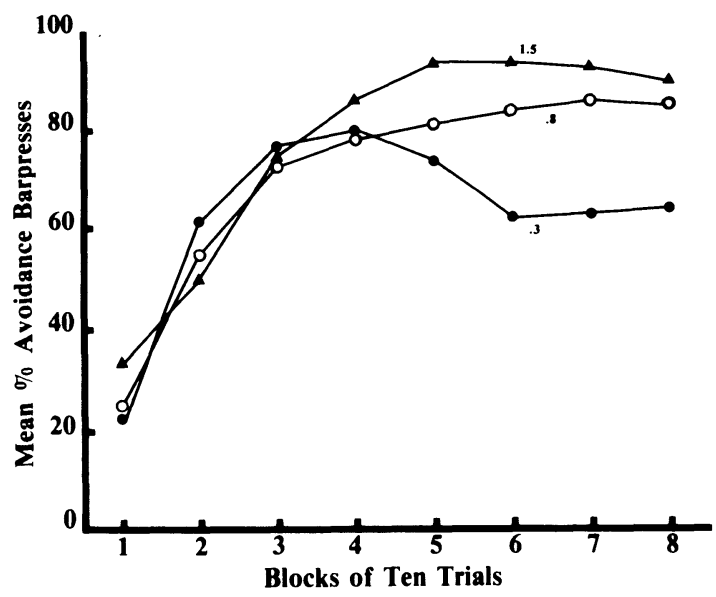

Figure 3. The mean percentage of avoidance barpresses in blocks of 10 trials, as a function of shock intensity, in Experiment 2. freezing reactions during the initial 20 trials. This conclusion would not, however, preclude the possibility that qualitative differences between barpress responses in the two groups (e.g., pulling the lever from below in Group E versus pushing the lever from above in Group R) differentially affected the strength of freezing reactions on subsequent trials and thereby resulted in different levels of avoidance responding.

The results of Experiment 2 showed that an increase in shock intensity has a positive, albeit weak, effect on elevated barpress responding. This finding leads to the possible speculation that, despite the apparent manipulative nature of an elevated barpress response in the present studies, the avoidance problem was solved by the subjects as a one-way locomotor task.

The ability of the subject to enter a safe dark platform may be construed as a powerful source of reinforcement (e.g., Masterson \& Crawford, 1982; W. R. McAllister, D. E. McAllister, \& Douglass, 1971), and the finding that shock intensity had a positive effect on avoidance responding may be taken as an indication that the more intense shock resulted in greater fear motivation (e.g., D. E. McAllister, W. R. McAllister, \& Dieter, 1976). The problem facing a reinforcement account of the present results is that the regular-lever subjects, despite experiencing nearly identical reinforcement conditions as did the elevated-lever subjects (Modaresi, 1989a), failed to show any avoidance learning.

\section{REFERENCES}

Bolles, R. C. (1970). Species-specific defense reactions and avoidance learning. Psychological Review, 77, 32-48.

Bolles, R. C., \& WARREN, J. A., JR. (1965). The acquisition of bar press avoidance as a function of shock intensity. Psychonomic Science, 3, 297-298.

D'Amato, M. R., \& Fazzaro, J. (1966). Discriminated lever-press avoidance learning as a function of type and intensity of shock. Journal of Comparative \& Physiological Psychology, 61, 313-315.

DIETER, S. E. (1976). Continuity and intensity of shock in one-way avoidance learning in the rat. Animal Learning \& Behavior, 4, 303-307.

FANSELOW, M. S. (1986). Associative vs topographical accounts of the immediate shock-freezing deficit in rats: Implications for the response selection rules governing species-specific defense reactions. Learning \& Motivation, 17, 16-39.

FANSELOW, M. S., \& LeSTER, L. S. (1988). A functional-behavioral approach to aversively motivated behavior: Predatory imminence as a determinant of the topography of defensive behavior. In R. C. Bolles \& M. D. Beecher (Eds.), Evolution and learning (pp. 185-212). Hillsdale, NJ: Erlbaum.

Masterson, F. A., \& Crawford, M. (1982). The defense motivation system: A theory of avoidance behavior. Behavioral \& Brain Sciences, 5, 661-696.

McAllister, D. E., McAllister, W. R., \& Dieter, S. E. (1976). Reward magnitude and shock variables (continuity and intensity) in shuttlebox-avoidance learning. Animal Learning \& Behavior, 4, 204-209.

McAllister, W. R., McAllister, D. E., \& Douglass, W. K. (1971). The inverse relationship between shock intensity and shuttle-box avoidance learning in rats: A reinforcement explanation. Journal of Comparative \& Physiological Psychology, 74, 426-433.

MODARESI, H. A. (1989a). The avoidance barpress problem: Elevated lever effect. Manuscript submitted for publication.

MODARESI, H. A. (1989b). The avoidance response problem: The role of species-specific defense reactions, reinforcement, and response position. Manuscript submitted for publication.

MODARESI, H. A. (1989c). Reinforcement vs. species-specific defense reactions as determinants of avoidance barpressing. Journal of Experimental Psychology: Animal Behavior Processes, 15, 65-74.

MOYER, K .E., \& KORN, J. H. (1966). Effect of UCS intensity on the acquisition and extinction of a one-way avoidance response. Psychonomic Science, 4, 121-122.

(Manuscript received August 11, 1989.) 